\title{
PROF. DR. PH. KOHNSTAMM EN DIE PERSONALISME.
}

"Ken die boom aan sy vrugte" is 'n gesegde wat ook waar is t.o.v. die groot geeste van die eeue. Kohnstamm is dan ook te ken aan sy werke, maar 'n kort uiteensetting van sy lewensgeskiedenis sou seker daartoe bydra om 'n beter insig te gee in sy werke self.

Philip Kohnstamm is gebore te Bonn in Duitsland in 1875. Sy vader, Max Kohnstamm, was vennoot by die bankiersfirma van Wertheim en Gompertz. Sy moeder was Sarah Wertheim, die suster van die hoofvennoot van die genoemde bankiersfirma. 
Die familie moes baie moeilike tye deurmaak vanaf Kohnstamm se geboorte. Gedurende al die donker tye was dit egter die voorbeeld van sy moeder, wat 'n blywende indruk op hom gemaak het.

In 1883 kom Kohnstamm op die laerskool te Amsterdam, daarna besoek hy die „Hoogere Burger School." Gedurende hierdie tyd het hy sigself veral aangetrokke gevoel tot die letterkunde, en die literêrmaterialistiese bewyskrag van Multatuli het veral by hom die drang tot natuurkunde en tegniek opgewek. Op advies van Prof. B. J. Stokvis (,oom Barend”) het Kohnstamm 'n verdere 5 jarige kursus gevolg aan die "Keizersgracht." Dit was veral gedurende hierdie tyd dat, nadat hy besonder sterk onder die invloed van Darwin gekom het, hy begin soek het na 'n Ideaal buite die natuur, wat sou dien as kompas om die lewe na te rig. ${ }^{1}$ )

Ook Dr. Doyer van Cleef, die leraar in skeikunde, het op hom besonder invloed gehad. Hieroor sê Hoogwerf: „Van dezen leraar fluisterden den jongens dat hij godsdienstig was, iederen Zondag nog naar de kerk ging, maar er nooit een woord over sprak. Deze ,achterlijkheid" van een overigens toch ,,gestudeerd mensch," was voor de leerlingen een geweldige sensatie, maar gaf den ernstigen onder hen toch te denken." ${ }^{2}$ )

Vanaf 1893 het Kohnstamm aan die "Gemeentelijke Universiteit" te Amsterdam studeer. Hier het hy veral onder die invloed en bekoring van twee groot geeste nl. Van der Waals en Bellaar Spruyt geraak. Veral was dit Van der Waals, wat fisikus van wêreldberoemdheid was, en tenspyte daarvan tog 'n gelowige Kristen, wat hier groot invloed op Kohnstamm gehad het. In die eerste jaar van sy universitêre loopbaan het Kohnstamm nog gemeen dat een van die stellings by sy promosie sou wees : "God is 'n hipotese." ${ }^{3}$ )

Op 20 jarige leeftyd maak die student in die wetenskappe kennis met die Bybel - hy was uit 'n huis wat al lang die Joodse ortodokse geloof ontgroei het. Sy belangstelling in die Bybel het veral gegroei deur die omgang met Van der Waals. Wetenskap was vir Van der Waals nie 'n saak van nut of middel tot beheersing van die natuur nie, dit was vir hom slegs diepere indringing in die grootheid en skoonheid van God se skepping. ${ }^{4}$ ) In Des. 1901 het Kohnstamm gepromoveer in die wis- en natuurwetenskap.

Intussen het Kohnstamm ook belang gestel in die filosofie. Prof. I. J. de Bussy het na die dood van Prof. Spruyt in 1899 aan Kohnstamm

1) Kohnstamm ,Individu E Gemeenschap” bls. 127 v.v

2) P. A. Hoogwerf „De Paedagogiek van Kohnstamm" bls. 5.

3) Kohnstamm: "Natuurwetenschap en Wêreldbeschouwing - Onze Eeuw" Oct. 1912 - blz. 195 v.v.

4) Kohnstamm: Het levenswerk van J. D. van der Waals - Onze Eeuw, jrg. 1923. No. 10 , bls. 3. 
die taak opgedra om verskiliende manuskripte van Spruyt saam te vat in 'n geheel wat sy denkrigtinge deeglik sou weerspieël. So het ontstaan "Geschiedenis der Wysbegeerte naar de dictaten van Prof. Dr. C. Bellaar Spruyt."

$\mathrm{Na}$ sy huwelik het Kohnstamm assistent geword aan die natuurkundige laboratorium van Van der Waals. Intussen het sy studie in die filosofie nie agter gebly nie. In die voorjaar van 1907 word hy privaat dosent in die filosofie aan die Gemeentelike Universiteit te Amsterdam. Sy openingsrede het gegaan oor Transcendenteel Idealisme: „De werkelijk in haar oneindigheid spot met alle beschrijving; $z i j$ kan nooit conform worden aan enige wetenschap, welke ook; zij laat zich niet vangen in een systeem van begrippen, d.w.z. begrijpen; zij is irrationeel." ${ }^{5}$ )

$\mathrm{Na}$ v. d. Waals se aftrede word Kohnstamm in 1908 buitengewoon hoogleraar in teoretiese natuurkunde. In hierdie jare vord Kohnstamm steeds meer en meer ' $n$ belangstellende student van die Bybel op grond van die diepe insig in die lewe, wat daarin te vinde is. Teenoor die belangstelling van die ..mens" Kohnstamm het egter gestaan die fisikus en wysgeer wie se taak dit slegs is krities-ondersoekend voorwaarts te gaan. Uit hierdie antagonisme het langsamerhand in sielskonflik ontstaan. ' $n$ sielskonflik wat s'egs opgelos is deur diepergaande kritiek.

Kohnstamm wys daarop dat wanneer hy, soos hy in sy werk doen. die Bybel durf noem 'n lamp vir sy voet en 'n lig vir sy pad, wanneer hy die naam van Kristen durf dra, dan is dit te danke, naas andere, vir nie 'n geringe deel aan die bevrydende werking van die Bybel kritiek. Uit die konflik hierbo na verwys, is hy deur kritiek bevry. Tans sien hy duidelik in dat hy die leiding van die Bybel mag aanvaar, hom geheel aan Kristus mag toevertrou, sonder ooit of ergens sy gewete te skend. Inteendeel, alleen daar is sy gewete veilig.

$\mathrm{Na} 1910$ het Kohnstamm ook met die politiek in aanraking gekom. Op propaganda-reise deur Friesland en Drente het hy met die volk in aanraking gekom. Op hierdie wyse het hy die intel'igensie en gesonde verstand van die onontwikk slde boer en aibeide= leer ken. Hy het die volk ontdek en dit is ook die uitgangstruit van Kohnstamm se liefde vir die volksopvoeder - Pestalozzi. Dit was Kohnstamm se bekering tot die opvoeding - sy roeping vir volksonderwys.

$\mathrm{Na}$ jare van arbeid in die wetenskaplike lewe, na jarelange worsteling met die diepste lewensprobleme, is Kohnstamm in 1917 gedoop en lid geword van die Nederduits Hervormde Kerk. ${ }^{6}$ ) Volgens Kohnstamm se eie lewensbeskrywing het die beslissing tussen die Joodse

5) ..Transcendenteel idealisme" bls. 22.

6) Hoogwerf, a.w. - bls. 17. 
godsdiens en die Kristendom reeds jare tevore plaagevind. Vir Kohnstamm is die Nuwe Testament die vervulling van die belofte.

Sy belangstelling in volksonderwys het toegeneem. In Januarie 1919 word Kohnstamm hoogleraar in paedagogiek aan die Universiteit van Amsterdam. In die praktiese wysbegeerte lê vir hom die moontlikheid van die pedagogiek. ,Slechts als deel der praktiese wijsbegeerte is de paedagogische wetenschap mogelijk; de paedagogiek zal philosophisch zijn of ze zal niet zijn." ${ }^{7}$ )

By welke filosofie die pedagogiek 'n aanknopingspunt moet soek, word deur Kohnstamm gevind op grond van sy jarelange soektog teneinde sy gemoed te bevredig met 'n lewensbeskrywing wat sou voldoen aan die vereiste van sy rede. Watter kragte beïnvloed ons lewe, vervul ons met eerbied, toon vir ons waardes aan, groter dan wat ons met die rede kan vermag? Vir K. lê die antwoord hier in die groot persoonlikhede. die helde van gees en hart, wie hulle norme ontleen aan die hoogste draers wat die mensheid deur die geskiedenis ken. Kohnstamm het sy lewens en wêreldbeskouing gevind en omsluit met die naam wat daarvan die diepste kenmerk vorm nl. die personalisme.

In 1932 word Kohnstamm hoogleraar in die pedagogiek aan die Universiteit van Utrecht as opvolger van die beroemde Nederlandse pedagoog Prof. Dr. J. H. Gunning W.z.

In voorgaande is getrag om enkele trekke in die lewensgeskiedenis van Kohnstamm aan te toon. Sy geskiedenis is die van 'n soeker en denker. Hierbo is aangetoon dat die personalisme die antwoord of uitslag was van sy vorsing na 'n lewens en wêreldsbeskouing. Die kernbegrip hier is die "persoonlikheid" en in wat hierop volg wil ons kortliks hierdie begrip en die verband daarvan met die teologie skets.

\section{Persoonlikheid: Religie en Teologie. ${ }^{8}$ )}

Hierby moet in aanmerking kom I Christelike en II nie-Christelike religies.

\section{Christelike religie en teologie.}

In die Christelike teologie is tot die 18 e eeu die woord "persoon" alleenlik gebruik in verband met die leer van die Drie-eenheid nl. om die drie eeenheid van die persone in die goddelike Wese aan te dui. Daarna eers word gespreek van 'n persoonlike God en die persoonlikheid van God, alhoewel die gedagte deur die eeue heen latent was in

i) Kohnstamm: Staatspaedagogiek of persoonlijkheids paedagogiek. b's. 6 .

s) Vgl. Skrywer se doktorale proefskrif „Opvoeding as vorming van die Sedelike Persoonlikheid" opgestel onder leiding van Prof. Dr. C. H. Rautenbach. Universiteit Pretoria 1944. 
die Bybelse teologie, en in alle geval deurgaans geopereer het in die religieuse lewe.

Die Bybelse voorstelling van die mens verskaf uiteraard die gegewens vir 'n besondere antropologie, in leer en beskrywing van die mens as persoonlike wese. Die mens geskape na die beeld van God ontvou hom as vrywillige, verantwoordelike wese met vatbaarheid vir kennis van goed en kwaad, dus sedelike persoonlikheid.

Maar dis merkwaardig dat ondanks die gegewens, selfs ondanks die feit dat die Bybelse openbaring histories is en aan persone verbonde is, die idee van die afsonderlike persoonlikheid nooit sterk beklemtoon word in die godsdiens van Israel nie, dat selfs die gedagte aan persoonlike onsterflikheid nie sterk op die voorgrond getree het nie.") Die ontdekking van die indiwidu. die indiwiduele persoonlikheid en persoonlike onsterflikheid is vir Berdyaev eerder in bydrae van die Griekse as van die Hebreeuse gees. By die Hebreër was dit die volk wat op die voorgrond was, alhoewel in sy heilige Boek die e'emente voorhande was vir in leer aangaande die mens as persoonlikheid. Maar dit het die Griekse gees geëis om iets van hierdie vorm van bestaan persoonlike lewe - $\mathrm{cp}$ die voorgrond te bring. Ook in dié opsig was die Griekse denke 'n voorbereiding vir die Christendom. Die Griekse denke het die Christelike denke bevrug. Die Christendom het op die duur die antropologie wat latent was in die Bybelse geskrifte op die voorgrond laat kom en alhoewel dit onder ander woorde uitgespreek was, is die grondgedagte dit: ,om mens te wees is om persoon te wees, en om persoon te wees is om verantwoordelik te wees teenoor God, die Skepper-Vader, in die gehoorsaming van Sy gebod, en wel in die verantwoordelikheid teenoor die medemens wat op jou weg gestel is."

Die Protestantisme het ook hierdie denkbeelde sterk vorentoe laat kom. Volgens die Christelike geloof in Protestantse sin is lewe, menselewe, dit om gedurig voor die vraag gestel te word: wat behoort ek te doen in die gegewe lewensituasies en omstandighede om die liefdesgebod van God te gehoorsaam? Sedelike verantwoordelikheid word gesien as 'n besondere aspek van die verantwoordelikho:d teenoor God. Die Christelike teologie vertoon natuurlik steeds cie spore van heersende geestes-strominge; al is dit dan net by wyse van verset. Die Christendom het 'n positiewe bydrae ge'ewer tot die lewensvisie van die Weste, ook deur sy opvatting van die persooniike God, wat weliswaar dikwels baie antropomorfisties voorgestel is, asmede sy leer aangaande die mens as geskape na die beeld van God, dis 'n per soonlike wese.

Op sy suiwerste word die Protestants-Christelike visie weergegre

9) Vgl. Berdyaev „Der Sinn der Geschichte” - Reichl; Darmstadt 1925. 
deur Emil Brunner. ${ }^{1 ")}$ Die verhouding van God en die mense stel hy aldus voor:

Wanneer die mens die oorsprong van sy lewe in God het, dan word die verhouding tussen God en die mens 'n persoonlike verhouding. Brunner beweer, o.i. ten onregte dat die idealistiese wysbegeerte alleen 'n onpersoonlike verhouding ken, want die grond van die dinge is vir die idealisme 'n idee, ' $n$ abstraksie. Maar, as die oorsprong van my lewe in God is, dan staan 'n Persoon voor my. In die ontmoeting met 'n ,U" word ek eers in die regte sin "n ,ek" d.w.s. 'n persoonlikheid. (vgl. ook die Bybelse Personalisme van Kohnstamm).

Daardie persoonlike verhouding beteken in verhouding van gebod en gehoorsaamheid, van woord en antwoord, van roeping en verantwoordelikheid.

Brunner beweer dat met hierdie persoonlike verantwoordelikheid iets anders bedoel is, as verantwoordelikheid in idealistiese sin. Waar ek met die grond van die dinge as $n$ idee te make het, daar bly ek in die grond van die saak by myself, in myself opgesluit, met as 't ware in muur om my heen. Verantwoordelikheid is dan in laaste instansie 'n verantwoordelikheid teenoor myself. Egte persoonlike verantwoordelikheid beteken dat die muur deurbreek word, deur verantwoordelikheid teenoor 'n Persoon. God, wat die grond van die dinge is.

Daardie persoonlike verhouding of verantwoordelikheid ontvang ek ook teenoor die naaste. Indien die muur wat ek om my gehad het deur die ontmoeting met die Persoonlike God deurbreek is, dan kan ek ook werklike persoonlike gemeenskap met die naaste hê. Ek word geroep om aan die naaste verantwoordelik te wees deur die feit dat God hom op my weg geplaas het. Hierdie liefde of verantwoordelikheid uit gehoorsaamheid is egte verantwoordelikheid en dit alleen is eg persoonlik.

Met die naaste kry ek te doen in bepaalde gegewe verhoudings w.o.

A. Die onpersoonlike doelgemeenskappe bv. verenigings en klubs.

B. Die natuurlike persoonsgemeenskappe.

(1) Geslagsgemeenskap, huwelik en gesinslewe.

(2) Die ekonomiese gemeenskap, maatskappy of werkgemeenskap.

(3) Die volks- of regsgemeenskap, die staat.

(4) Die Kultuurgemeenskap en

(5) Die Geloofsgemeenskap of Kerk.

Brunner se gedagte kan só saamgevat word:-

Mens wees $=$ persoon wees $=$ verantwoordelik wees teenoor God

10) Brunner: .Das Gebot und die Ordnungen" - Tübsingen 1933. Engelse vertaling ..The Divine Imperative." 
$=$ verantwoordelik wees teenoor die medemens in die gegewe gemeenskapslewe.

Die suiwer etiese, die sosiaal-sedelike in hierdie gedagtegang het deel geword van die geestesgoed van die weste. Die Christendom het op sy beurt invloed gehad op die Wysbegeerte, insonderheid die wysgerige besinning oor die aard, status en bestemming van die mens.

\section{Nie-Christelike Religie en denke.}

Dit is merkwaardig dat die Weste wat vir baie eeue die Christelike invloede ondergaan het, met sy besondere beskouing oor die verhouding enkele-gemeenskap, juis veel meer indiwidualisties is as die Ooste, veral die Verre-Ooste. Die ondersoek van die indiwidualisme van die Europese mers is ' $n$ groot afsonderlike studie. Wellig is die trek to indiwidualisme sterker by die Europese as by die Asiaticse mens. Sommige wil die wortels daarvan soek by die Griekse erfenis wat met die Renaissance meer ingedra is in die Weste. Ander vind dat bepaalde vorms van die Protestantisme juis indiwidualisme bevorder het. (vgl. Max Weber ,The Ethics of Protestantism). Hoe dit ook sy mens kan met reg verklaar: Soos vir die 19de eeuse Weste die radikale indiwidualisme kenmerkend was en tans ook nog nawerk, so is vir die Ooste - die Asiatiese mens - 'n kosmiese gemeenskapsbesef, karakteristiek nl. die besef van lid te wees van 'n alorganisasie. ${ }^{11}$ )

Soepoma (De verhouding van individu en gemeenschap in het adatrecht, 1941), aangehaal deur Rasker bogenoem, verklaar dienaangaande „Het individu word in de eerste plaats gezien a's orgaan van de gemeenschap, als levend werktuig om de doeleindes van de gemeenschap te verwezenlijken... Deze gemeentschapsdiensten zijn naar het bewustzijn van het individu echter niet zozeer lasten, die hem door een buiten hem staand gezag zijn opgelegd. , $Z_{i j}$ hebben niet het karakter van "offers" die het individu ten bate van de gemeenschap zou moeten opbrengen. Naas het volksbesef zijn de gemeenschapsplichten eenvoudig natuurlijke functies in het leven van den mench...

Voor het nog niet geïndividualiseerd Indonesisch bewustzyn bestaat geen tegenstelling tusschen gemeenschap en individu. De gemeenschap word niet geobjectiveerd als een afsonderlijk individu met een eigen belangensfeer. $Z_{i j}$ is niet een macht, die los van en tegenover de in dividuele menschen staat. Neen, de individuen voelen zich voor alles één met de groep. $Z \mathrm{ij}$ weten zich en leven als organische deelen van het geheel....

Dit wil niet zeggen dat er geen bewustzijn van individualiteit is. De enkeling heeft ook ruimte voor een individuele levenssfeer. Dit is

11) Dr. A. J. Rasker: "Theologische Stemmen" - Batavia 1941. Jaargang 1. No. 4. Pag. 122. 
niet overal even sterk... in de steden sterker dan in die dorpen, bif: intellectueelen sterker dan bij onontwikkelden.. Verder neemt de individualisatie toe door economiese ontwikkeling, Westersch onderwijs. en den invloed van Islam en Christendom" ens.

Terloops, in die Weste ontplooi die twintigste eeu hom tans as 'n bestryding van die radikale indiwidualisme van die neëntiende eeu.

Die Oosterse kosmiese gemeenskapsbesef, soos Rasker dit genoem het, toon merkwaardig veel ooreenkoms met die dominerende Oosterse religieuse lewensvorme. Dié religieuse beskouing omsluit dit dat God gedink word as die kosmiese bewussyn, wat eerder onpersoonlik as persoonlik gedink word. Om dieper in te dring in die werklikheid beteken om opgeneem te word in die kosmiese bewussyn, wat nie die bewussyn van ' $n$ persoon is nie. Die visie van die diepste realiteit as persoonlik sou dan hoort by 'n mindere graad van mistieke ervaring.

Die kosmiese bewussyn is ook die diepste kern van 'n mens se eie wese, wat mens ontdek deur opgeneem te word in die eersgenoemde. Die ego-sentriese bewussyn van die indiwiduele persoon is ' $n$ fragmentariese en verbygaande ,.ek" wat lewe in 'n fiktiewe skynwêreld. Indiwudu te wees, aparte en afsonderlike. .ek" wees is kwaad en 'n skynbestaan, en die roeping van die gees is om die bande van apartheid te verbreek en op te gaan in die universele al-gees.

In dié opsig is daar dan 'n sterk teenstelling tussen Europese en Asiatiese mens, soos blyk in die respektiewe tipiese godsdiensvorme. Die Christendom styg tot sy hoogste in die gewyde persoonlikheid, wat sig in aktiewe gehoorsaamheid aan die Persoonlike God weerkaats: die Hindoeisme tot ontlediging van die persoonlikheid in eenwording met die Al-gees wat onpersoonlik is. ${ }^{12}$ )

By wyse van afsluiting moet gesê word dat die begryp ,persoonlikheid" vir die gerypte en besonne Europese denke, én die individueel gerigte of egosentriese én die bowe-indiwiduele gerigte — sosiale en supra sosiale tendense omsluit. Die Westerse opvatting van die sedelike persoonlikheid soos uit die Etiek op te makk is, is juis die van 'n persoonlikheid waarin die sosiale en supra-sosiale domineer oor die indiwidueel-gerigte neiginge. Dit blyk ook daaruit dat die kragte wat in die. Weste gesluimer het tans die stryd aanknoop teen die radikale individualisme.

C. E. PRINSLOO

12) Joad - God and Evil; London 1942. 